\title{
H umanismo, liberdade e necessidade: compreensão dos hiatos cognitivos entre ciências da natureza e ética
}

\author{
H umanism, freedom and need: \\ an understanding of the cognitive gaps \\ between the natural sciences and ethics
}

Ana Maria C. Aleksandrowicz 1

M aria Cecília de Souza M inayo 2

\footnotetext{
1 Escola Nacional de Saúde Pública, EN SP/Fiocruz. Rua Leopoldo Bulhões 1.480, $M$ anguinhos, 21041-210, Rio de Janeiro RJ. analeks@unisys.com.br ${ }^{2}$ Centro Latino-Americano de Estudos sobre Violência e Saúde, Escola Nacional de Saúde Pública/Fiocruz.
}

\begin{abstract}
The growing ascertainment, guided by the natural sciences, of the determinism that rules how living organisms work is often contrasted with a humanism of Kantian foundation. At issue here is the actual condition of human autonomy, reverberating on that of human responsibility both at the social and at the individual levels. Based on Spinozist philosophy, Atlan endorses the deterministic postulates of scientific investigations, though he reconciles them to the statement of the human being's full freedom and responsibility. Initially, with the strategic background of distinctions in conceptions of human nature, we will review the different approaches of autonomy and determinism on the part of ethics and science. We will then concentrate on the discussion of the dilemma by Atlan, in his essay of 2002, La Science est-elle Inhumaine: essai sur la libre né cessité. Our conclusion redefines the meaning of "humanism" pursuant to the new conceptual demands of the 21st century.

Key words Science, Ethics, Freedom, N ecessity, Complexity
\end{abstract}

Resumo Com freqüência opõe se a constatação crescente, norteada pelas ciências naturais, do determinismo que rege o funcionamento dos organismos vivos a um humanismo de fundamentação kantiana: está em questão a real condição da autonomia humana que repercute naquela de sua responsabilidade individual esocial. Com basena filosofia espinosista, Henri Atlan endossa os postulados deterministas das investigações científicas, conciliando com eles, entretanto, a afirmação da plena liberdade e responsabilidade do ser humano. N um primeiro momento, tendo como pano de fundo estratégico distinções nas concepções de "natureza humana", revisaremos as diferentes abordagens da ética e da ciência às teses da autonomia e do determinismo. A seguir, focalizaremos a discussão do dilema por Atlan, em seu ensaio de 2002, La Science est-elle inhumaine? Essai sur la libre nécessité. Concluímos ressignificando "humanismo" nos termos das novas exigências conceituais do século 21.

Palavras-chave Ciência, Ética, Liberdade, $\mathrm{Ne}$ cessidade, Complexidade 


\section{Introdução}

A existência humana, que se desenrola na duração pode ser a ocasião de uma procura de perfeição cada vez maior, de uma história de salvação e deliberdade, onde as exi gências mais altas da ética tendem a encontrar a experiência e o conhecimento das leis da natureza (H enri Atlan, 2002).

0 papel da ciência e da filosofia será o de nos fazer aceder com a ajuda da Razão a um conhecimento do bem edo mal que seria verdadeiro porque decorrente da "verdadeira" natureza do homem (...) No contexto da ética, acontece que o que a Razão nos mostra como sendo o mais útil ao homem são os outros homens (Henri Atlan, 1999c).

Este número temático problematiza a noção de humanização, hoje largamente utilizada na área da saúde coletiva. Ela é considerada fundamental nesse campo estratégico de aplicação de conhecimentos voltados para a promoção da qualidade de vida. Tomada como consigna que reúne, de forma implícita, qualidade da atenção, interação compreensiva entre profissionais de saúde-pacientes e revalorização do olhar clínico, no mundo proeminente das tecnociências e das biotecnologias, "humanização" entrou no jargão do planejamento e da gestão do setor saúde. Este artigo aborda o tema pelo lado dos seus fundamentos, trazendo para o debate a contribuição da filosofia e da antropologia.

A concepção de "humanismo" surge na atmosfera de ebulição do Renascimento, paralela ao nascimento da ciência moderna, instaurando a noção da dignidade humana e erigindo a realização do potencial natural do ser humano como meta intelectual. Embora o sucesso do termo muito deva aos progressos científicos associados a este período da História, o "naturalismo" renascentista que permeia a valorização do humano insere-se numa ontologia mágica, onde tudo é possível (Koyré, 1991). A participação do "novo homem" dos séculos 15-16 no desenvolvimento científico é mais sutil: sob os auspícios dos procedimentos "(sobre) naturais" investigados, ter-se-ia começado a estimular a ação no mundo através da passagem da teoria à prática, ou seja, da aplicação dos conhecimentos para produzir operações (em evidente contraste com a tradição grega) (Yates, 1964). A partir de então, irá progressivamente consolidar-se na mentalidade pós-renascentista uma direção de vontade não mais grega ou medieval, impelindo à manipulação e modificação da natureza; nos subterrâneos desta atitude, estaria a convicção crescente de que a única restrição cabível ao empenho humano é aquela estabelecida por sua própria decisão.

Levemente tingido de sua origem retórica, 0 humanismo contemporâneo, reavivado pelo recurso constante ao "reino dos fins" kantiano, constitui-se numa ampla e secular antropologia filosófica e filosofia social (Bunge, 2002). A leitura epistemológica mais sofisticada do humanismo apóia-se na assertiva protagoriana de que o homem é a "medida das coisas" para propor uma perspectiva pragmática na apreciação do conhecimento, que estaria subordinado em definitivo à natureza humana eàs suas necessidades fundamentais (grifo nosso) (Schiller, 1917, apud Lalande, 1988). M as a versão que prosperou recentemente foi a que privilegia suas dimensões éticas e sociais, fortemente influenciadas pelo existencialismo e pelo marxismo, segundo os quais, o homem cria o seu próprio ser, pois o humano, através da história, gera sua própria natureza (grifos nossos) (Japiassu, 1998). No final do século 20, o termo foi amiúde ridicularizado por movimentos pós-modernos e multiculturais, adeptos das teses da incomponível fragmentação da personalidade e da motivação, flutuantes ao sabor de condicionamentos históricos irregulares (Blackburn, 1997).

Embora sempre se pretendendo alicerçado, como estivemos sublinhando, na especificidade da "natureza humana", o "projeto humanista" filiou-se tradicional mente ao campo das humanidades, sendo o predomínio crescente de uma decodificação do mundo norteada pelo viés científico considerado com suspeita. Em searas acadêmicas, a principal crítica é a de que a ciência justifica filosoficamente sua posição real ista e utilitária face ao problema do conhecimento pelo que Searle (2000) chama de "posições-padrão". Estas seriam as opiniões que temos antes da reflexão, de modo que qual quer desvio delas exige um esforço consciente eum argumento convincente. Os cientistas usualmente estruturam suas práticas tendo por "pano de fundo" de seu pensamento e linguagem tais posições-padrão que só são modificadas por um algum ponto de vista novo e revolucionário (Searle, 2000), ou seja, sob o influxo da mudança de paradigma kuhniana. M as, dada a confortável separação funcional - que detal haremos adiante - das Ciências e das H umanidades, a não ser em redutos acadêmi cos restritos, as conclusões científicas e 
as extrapolações humanistas não se punham em xeque, embora as últimas já estivessem desgastadas pel os desconstrutivismos pós-modernos.

Apenas quando desabrocha, na vicejante brotação neodarwinista, a antiga curiosidade sobre a "natureza humana" que modelara suas raízes na História $\mathrm{N}$ atural, a biologia evolutiva rompe a trégua instável entre as disciplinas "humanas" e "científicas". U m dos pomos da discórdia é justamente a autonomia da vontade humana - um dos motes diletos do humanismo. Diante dos extraordinários avanços desta área da Ciência, na passagem dos séculos 20-21, o desafio recoloca-se num patamar inédito de complexidades. Agora, por um lado, a biologia evolutiva (centrada na biologia molecular) invoca uma ampla competência para codificar ou mesmo negar a natureza humana (Pinker, 2004), postulando determinismos genéticos e agregando ao contexto de características adaptativas da espécie comportamentos antes considerados "desumanos" como aqueles ditados por "egoísmos" radicais. Por outro lado, no âmbito de nossas experiências existenciais cotidianas, urge redefinir pressupostos teóricos que, sem contrariar os dados científicos, nos reassegurem da condição humana de ir além, rumo à Felicidade, do que seria uma descrição simplista, por insuficiente, de sua natureza.

0 problema filosófico, pois, que estaria no cerne das disputas entre H umanismo e Ciência seria o que opõe autonomia a determinismo. A tensão entre estes dois termos, demandando uma revisão consistente da seleta gama de conceitos que os traduzem e esculpem - tais como livre-arbítrio, liberdade, escolha, necessidade e responsabilidade - parecenos capaz de impulsionar reviravoltas conceituais e filosóficas decisivas na alteração de visões do mundo, refletindo-se nas próprias experiências existenciais individuais e sociais. Com efeito, qualquer investigação sobre a possibilidade humana de direcionar livremente os atos do indivíduo em prol de uma ética de respeito e solidariedade para consigo mesmo e o seu semelhante, conduzindo ao bem-estar e à felicidade, repousa sobre a questão fundamental da autonomia e do determinismo. No entanto, esses conceitos filosóficos são freqüentemente negligenciados nos bem-intencionados apelos atuais a uma renovação do humanismo ou a mesmo uma humanização pragmática e/ou funcional de nossos comportamentos.

A contribuição de Henri Atlan na presente discussão é inquestionável. Em sua qualidade de biofísico ativo na pesquisa laboratorial, este autor depara-se com a constatação crescente, norteada pelas ciências naturais, do determinismo que rege o funcionamento dos organismos vivos. Como filósofo espinosista transcreve, nos termos do racionalismo espinosista (distinguindo-o substantivamente do kantiano), as condições para a liberdade humana e suas repercussões na atribuição de responsabilidades individuais e sociais. Seu grande mérito é proceder a um giro conceitual surpreendente, conciliando as hipóteses científicas mais audazes a uma exigência ética impecável.

Em nossa defesa do "projeto atlaniano", num primeiro momento, tendo como pano de fundo estratégico distinções nas concepções de "natureza humana", revisaremos as diferentes abordagens da ética e da ciência às teses cruciais da autonomia e do determinismo. Em nossas considerações finais, reconceituamos o termo "humanismo", em sintonia com seus mais estimulantes desafios filosóficos e antropológicos, na aurora do século 21.

\section{Descrições da "natureza humana" pela ciência e pela ética}

Dentre as questões filosóficas "perenes", uma das mais fecundas diz respeito ao conceito de "natureza humana". Em consonância com o que, de acordo com a tese que encampamos, constituiria o imperativo cultural do Ocidente - o entrelaçamento razão-ciência a partir da busca grega do conhecimento da natureza (Bloom, 1987), esta indagação vem eivada de uma outra, também central para as decodificações da realidade: 0 confronto entre determinismo eliberdade. Cria-se, no momento filosófico inaugural, a aporia clássica: quanto mais a razão descobre um mundo regido por leis correspondentes a sua capacidade teórica de formulá-las, tanto menos, sob o ponto de vista de seus interesses da vida ordinária, aí incluídos os atos de "escolha" humanos, a mesma razão pode se subtrair ao reconhecimento da supradeterminação da natureza (Santos, 2002). Entretanto, cumpre reconhecer no homem a responsabilidade por seus atos, já que esta é o fundamento da vida moral e social, princípio simétrico ao da liberdade humana - outra contribuição inalienável de legado helênico.

0 debate entre determinismo e liberdade se instaurou de forma toda particular entre os estóicos e Aristóteles. Os primeiros insistiam em 
conciliar a responsabilidade moral com um destino universal eimutável, uma vez que o homem é parte do mundo natural. A virtude humana se expressaria no acordo profundo consigo mesmo e com a $\mathrm{N}$ atureza que é, intrinsecamente, razão, donde rigorosamente predeterminada (Aubenque, 1978; Brun, 1958). Na física estóica, o destino corresponde a um encadeamento (ordem e ligação invioláveis) de "causas". O bserve-se que não se tratava de causas finais; a palavra que se traduz por causa, "aition" significa literalmente "aquilo que é responsável" (Long\&Sedley, 2001). Já para A ristóteles, o homem, "animal social por natureza" (Política, 1.253a, livro I, cap.1§9), só adquire a verdadeira humanidade na sociabilidade. Por isso, torna-se conveniente a uma vida moral propícia à pólis, definir e defender um conjunto de categorias concernentes às condições para uma "ação voluntária" de maneira a se recusar o império do determinismo (M uñoz, 2002).

No período medieval predominaram versões aristotélicas laicas ou cristãs, embora, ao longo da história das idéias no 0 cidente, a tensão entre as duas posições tenha sido constante. No início da M odernidade, enquanto a visão cartesiana do mundo natural mantinha-se rigidamente determinista, a separação imposta pelo filósofo entre natureza (res extensa) e pensamento (res cogitans) permitiria ao sujeito racional, através da certeza ontológica do cogito, ter garantias crescentes de seu poder de livre-arbítrio (Bornheim, 1997), o que distinguiria a "natureza" humana da natureza físico/química. Com a concepção kantiana de autonomia, regalia do indivíduo racionalmente cultivado e amadurecido, chega-se ao auge desta tendência. Kant (1971) proclamará, quanto aos obstáculos à propagação da ilustração (enlightenment): I sto seria um crime contra a natureza humana, cujo destino original repousa precisamente neste progresso (grifo nosso). Com Kant cristaliza-se uma dissociação fundamental entre a natureza físico-química - predeterminada - e a "natureza humana", voltada ao acesso exclusivo ao supra-sensível domínio da liberdade (Atlan, 1999b). Na visão kantiana, a capacidade racional - desde a aurora grega reconhecida como a especificidade radical do ser humano na natureza - entrelaça-se com a pretensão de livre-arbítrio nas ações e intervenções humanas entre si e no mundo natural circundante.

No mesmo período, estabelecem-se as bases da ciência moderna, herdeira da filosofia natural, do fértil intercâmbio entre a elaboração ma- temática de Galileu, a visão de mundo dualista cartesiana e o desenvolvimento da física newtoniana, desde Bacon fundamentada através da tecnologia (Oliveira, 2002; Oliva, 1990). A natureza passa a ser descrita como um mecanismo em funcionamento, delimitada num espaço geométrico, no interior do qual as relações entre objetos são governadas deterministicamente por uma causalidade cega (Japiassu, 1998). Esta percepção contrasta vivamente com um ímpeto humanista coetâneo, sedento de desvencilhar-se do jugo religioso aliado ao organicismo deAristóteles e da escolástica.

A partir de então as disciplinas que estudam o homem irão se enredar numa das mais formidáveis (e produtivas!) contradições da cultura ocidental. Ao mesmo tempo em que tomam de empréstimo das ciências naturais os métodose conceitos que al icerçam o crescente conhecimento e controle das leis (determinísticas) da natureza, as ciências humanas pretendem colocar estas mesmas leis a serviço da "liberdade" humana. Para tal, norteiam-se por um entendimento kantiano de razão que intenta alijar de si o "mecanicismo" - termo tornado pejorativo quando associado ao humano, extraviado de sua conotação original, grega e árabe, de "engenho" comparável ao exercitado na medicina e na arte (Losano, 1990) - da natureza. 0 termo Humanidades reveste-se, então, da pretensão de formação (Bildung) da personalidade do homem independentemente de qualquer finalidade utilitária - competência científica ou prática (Rouanet, 1987).

É sob a égide deste descompasso que se dará a famosa cisão entre "as duas culturas" ou entre as assim chamadas ciências da natureza e as ciências humanas e sociais - ou seja, as ciências do espírito, como as denominaria Dilthey (1944) no século 19. É relevante acompanhar, com Renault (1998), a formação da "inédita representação da liberdade humana" na modernidade. Conforme a acepção grega de liberdade, Aristóteles comparara o universo a uma ca$\mathrm{sa}$, os homens livres representando os astros, "porque lhes émenos lícito agir ao acaso" e porque todas as suas ações - ou, pelo menos, sua maioria - são regradas (M etafísica, A, 1075 a 1922). São, pois, os escravos que são livres no sentido moderno da palavra, porque não sabem o que fazem, ao passo que a liberdade do homem grego e sua perfeição são medidas de acordo com a determinação maior ou menor de suas ações ( $\mathrm{Au}$ benque, 1963, apud Renault, 1998). Já sob a tônica pós-kantiana, nos séculos que se Ihe segui- 
ram, (n)a nova liberdade, a humanidade quer assegurar-se do desenvolvimento autônomo de todas as suas faculdades para exercer seu domínio sobre a Terra (H eidegger, 1971, apud Renault, 1998).

Os estudos em filosofia moral espel hariam estes deslocamentos conceituais. $\mathrm{Na}$ Grécia, tanto a natureza do U niverso como a natureza do homem - em sua dupla expressão, traduzida pelo lógos, no cosmos e na pólis (Jaeger, 1989) finalizava-se no nível da perfeição. Essa ambição, na esfera do indivíduo, traduzia-se na obtenção de comedida felicidade. Segundo tal modelo ético, de feição ontológica, o homem alcançaria a plenitude de sua natureza ou finalidade na contemplação - entre os estóicos, na ataraxia - ou na vida social justa. Tal paradigma opõe-se, por definição, ao kantiano, no qual a ética é fundada no cumprimento da lei e 0 acesso à felicidade, irrelevante. Se o primeiro paradigma fundava-se numa epistemologia naturalista, o segundo absorve os problemas de um mundo organizado com base no contrato social (Pegoraro, 1997).

$\mathrm{Na}$ cúspide da íntima conjunção existente nos séculos 17 e 18 entre a "ciência moral" e o "direito natural", surge uma concepção de natureza humana de larga influência no debate político e ético posterior. Segundo esta interpretação, o ser humano possuiria, desde seu nascimento, prerrogativas a el e conferidas pelo "direito natural" como um imperativo da natureza humana, dotada de propriedades inatas e universais que exigem correspondência institucional e substantiva nos corpos políticos artificiais e nas leis positivas que os instituem ( grifo do autor) (... donde...) um conjunto de valores (...) passou a circunscrever a condição humana (grifo nosso) (Lessa, 2003). Tendo-se afastado de sua aliança com a ciência/filosofia moral, as ciências sociais preferiram referir-se à "condição humana" para enfatizar o cunho conjuntural e provisório da atribuição de uma dada "natureza" aos membros da espécie humana. Entretanto, o problema de um "destino" evitável introduz-se constantemente na reflexão, embebido no imperativo político de facultar a todos os homens a liberação da barbárie e do sofrimento (Elias, 1985). Esta preocupação avulta em autores como M arx e $\mathrm{H}$ egel, para os quais a história se desenvolve segundo um plano imanente, necessário e favorável. 0 materialismo dialético forneceria uma associação explicativa entre a história humana e a do cosmo que obedeceriam às mesmas leis eternas (Bornheim, 1997).
No século 20, verifica-se uma virada decisiva no estatuto da $\mathrm{N}$ atureza a partir do entendimento do papel do ser humano, como observador participante e agente, dentro de um universo regido pelas leis da "nova física", formulada pelas teorias da relatividade e do caos e pela mecânica quântica, às quais logo veio unir-se a reflexão da "nova biologia" molecular. N enhuma descrição da realidade pode mais se eximir de levar em consideração os conceitos inéditos emergentes destas disciplinas (Searle, 2000).

Ainda insuficientemente avaliado, este "giro epistemológico" provoca uma verdadeira revolução nas concepções vigentes de natureza humana e dos temas a ela associados como o determinismo e o livre-arbítrio. Até certo ponto, retoma-se 0 ancestral ideal grego de compreensão integral da Natureza (reincorporando-se substantivamente o ser humano à sua esfera) ao mesmo tempo em que se recusa, ao menos teoricamente, a continuação da exploração indiscriminada dos recursos naturais (aqui também incluída a espoliação humana), antecipando-se o desenvolvimento da consciência e dos movimentos ecológicos. Pode-se mesmo falar de um ensaio de retorno a uma experiência das relações entre homem-natureza na ordem da antiga physis, o que constituiria a "nova aliança", alinhavada por um químico e uma filósofa (Prigogine $\&$ Stengers, 1984), de forma a aproximar estatutos fundamentais das ciências físico-químico-biológicas e das humano-sociais. A proposta é conciliar o que seria um aparente determinismo das primeiras com a suposta indeterminação ou acaso ontológico das segundas presumivelmente assim atestando a natureza ontológica da liberdade, donde das ações/decisões humanas.

Este equívoco interpretativo já tem sido suficientemente dirimido, pelo esclarecimento de dois aspectos fundamentais: 1) o papel do observador na física quântica não significaria qualquer interferência de uma "subjetividade" no fenômeno e sim a aferição objetiva de dados por aparel hos de medição criados pelo homem (Atlan, 1979); 2) nos contornos do "caos determinista", verificado nos eventos complexos de processos físico-químicos e biológicos, a existência da aparente al eatoriedade corresponde apenas à nossa ignorância da precisa organização das leis que os determinam (Atlan, 1995).

U m viés de particular interesse é o fornecido pela retomada do tradicional problema corpo-mente instaurado na filosofia cartesiana ou seja, a compreensão do lugar que a mente 
ocupa na natureza (Blackburn, 1997) - por neurocientistas, filósofos da mente e psicólogos cognitivos. Quanto mais a neurociência comprova as conexões causais entre o funcionamento do cérebro e as funções mentais (e comportamentos a elas correspondentes), mais se é tentado a valorizar o componente biológico da experiência mental, sendo o estudo da natureza humana reinserido vigorosamente, através de critérios mecanicistas, num estatuto prioritário das ciências naturais. Programas de pesquisas nesse sentido diversificam-se enormemente, em pelo menos dez diferentes doutrinas associadas quer ao monismo, quer ao dualismo corpomente (Bunge, 2002). Eles abrangem desde propostas de naturalizar a epistemologia, desafiando a falácia naturalista (Abrantes,1993), até as mais originais possibilidades de aproximar ou contrapor os postulados das ciências naturais e das ciências humanas e sociais (Dennett, 1991; 1997; 1998; Edelman, 1992; 2000; Searle, 1995; 1997; 2000). A posição com a qual Atlan se afina não pretende que as conclusões das neurociências e ciências cognitivas sejam suficientes para explicar a experiência subjetiva e os dilemas éticos.

0 predomínio atual das ciências biológicas nas decodificações da real idade avulta através das celeumas em torno das conquistas das Biotecnologias, às quais se credita uma capacidade de transformação inaudita da "natureza humana" - contrastando com o ponto de vista evolutivo, segundo o qual esta se vem modificando constante e ininterruptamente (Atlan, 1999d). Ao invés, proclama-se o quanto nossa espécie teria alterado a ordem "natural" de sua existência por meio da tecnologia: drogas, peças de reposição para virtualmente todos os sistemas corporais, técnicas de reprodução assistida e promessas de clonagem. Variados rótulos, quais "pós-humano", "pós-orgânico" e "pós-biológico", circunscrevem a nova condição humana (Kurtweil, 2003; Sibilia, 2002; Santaella, 2003), que, à primeira vista, propiciaria maior autonomia do indivíduo, uma vez que Ihe seria viável adiar ou modelar opções existenciais, de forma inédita.

Entretanto, desde logo, um entendimento bastante parcial do conceito de determinismo assombra estas perspectivas. As conquistas da biogenética, da engenharia molecular e da nanotecnologia parecem garantir uma evolução que não seria mais a natural, que poderá levar a uma outra natureza humana, sendo a grande questão quem vai entrar nesta outra natureza humana (Santos, 2003). Vai-se ao encontro, aqui, do "conservadorismo naturalista" (Hottois, 2003) de Fukuyama (2003) e de Habermas (2004), que, sob o pretexto de defesa da "natureza humana" (assimilada a nosso "patrimônio genético único"), partilham a tese de que nossa dignidade só pode ser mantida se conservarmos a indeterminação da disposição genética. Segundo estes pensadores, devemos nos abster de controlar qualquer aspecto de nossa identidade por meio de manipulação biotecnológica, o que significaria renunciar ao que conhecemos dos determinismos genéticos para evitar sua utilização inadequada.

Zizek (2003) evidencia, antes de tudo, a impossibilidade de retorno a um "imediato ingênuo", já que sabemos que nossas ten dências naturais dependem da contingência genética. Agir como se não fosse o caso, além de falso, em última análise estaria limitando a nossa autonomia e liberdade de intervenção científica, com base em um argumento conservador, obscurantista, segundo o qual seria melhor "escolher ignorar". Com tal postura, evita-se enfrentar a verdadeira pergunta: Como estas novas condi ções nos forçam a transformar e reinventar as próprias noções de liberdade, autonomia e responsabilidade ética? (Zizek, 2003)

Paralelamente, diversas orientações interdisciplinares vêm, desde a década de 1950, pesquisando os sistemas complexos de que os seres vivos fazem parte, sob uma diretriz da Biologia mais atenta à importância dos conceitos (como os de "sel eção natural" e "programa genético") na gênese de suas teorias ( $M$ ayr, 2004; Atlan, 1999e). Dentre elas, estão os estudos de auto-organização, centrados em torno da intuição de que novas estruturas e funções podem emergir da própria dinâmica dos elementos que as constituem, de maneira a que a natureza física-química-biológica e a natureza humana entrelacem-se, sem se confundir, em níveis cada vez mais complexos de organização (Aleksandrowicz, 2002). As questões do determinismo e da autonomia, neste quadro de referências, são transcritas conforme os códigos das ciências que investigam os diferentes níveis onde os fenômenos relativos aos seres vivos ocorrem, progressivamente do molecular ao psíquico esocial, levando-se em conta sua pertinência para previsão e controle - e/ou para a atribuição de significados a atos de indivíduos e grupos sociais.

0 conceito de "emergência" é nuclear para esta perspectiva, assim como um forte viés epistemológico, segundo o qual o conhecimento dos 
determinismos é sempre relativo às possibilidades de observação e recorte pragmático de variáveis no nível em foco do fenômeno estudado. Assim, devemos fazer uma distinção entre as camadas de previsibilidade e as camadas que são pequenas demais ou complexas demais para permitir previsão. Quanto à relação entre a natureza ea cultura este argumento implica que devemos considerar a sociedade como extensão do mundo natural e de (suas) regularidades (...) ainda que as sociedades sejam complexas demais para permitir qualquer forma de previsibilidade (M anifesto de Stanford, 2003). Como regra geral nesta vertente, silencia-se suavemente acerca das possibilidades de autonomia humana: não se pode excluir o ser humano da lógica determinista vigente para as outras esferas da natureza, nem ignorar o seu anelo infinito pela liberdade, eliminando-a em termos ontológicos. É neste hiato que viceja a proposta inovadora deHenri Atlan.

\section{0 "giro epistemológico" da hipótese radical de Henri Atlan}

H enri Atlan ocupa uma posição privilegiada, como expoente quer da Biologia molecular (H ospital H adassah, Jerusalém), quer da Filosofia e da Ética da Biologia, cadeira criada sob a inspiração de sua obra na EHESS, Paris. Em Israel, chefia um departamento de pesquisa de ponta em Biofísica, onde criou um modelo pioneiro de subdeterminação das teorias pelos fatos, aplicando o formalismo das redes neurais à imunologia (1989, 1991b, 1993, 1999e), de forma a dar suporte à sua teoria física da intencionalidade (1998a, 2003b). N esta, assim como em suas incursões ao problema corpo-mente mediado pela filosofia da linguagem (1998b, 2003b), defende uma perspectiva determinista acerca de como se processam opções e ações no ser humano. Já em Paris, propõe uma estratégia epistemológica e existencial de "relativismo relativo" (1991a) na abordagem de conflitos de valores entre indivíduos e/ou grupos sociais e na dos dilemas ditos bioéticos (1995, 1999b, c, d). Norteados pelo "relativismo relativo", significados como o de "escolha" e "consenso" impressos aos atos humanos assumem importância visceral, principalmente quando são solicitadas soluções éticas/políticas acerca de "direitos humanos" (1995, 2003b). É a sua teoria de auto-organização dos seres vivos (em processo de refinamento desde 1972) - inserida com rara sofisti- cação intelectual nos estudos dos sistemas complexos (1991c) - que lhe permite ir além da aparente dicotomia entre o registro científico e 0 ético, conciliando-os sem confundi-los, cada vez mais consistentemente embasados na filosofia espinosista.

Aliando-se a Spinoza, Atlan considera que o poder de ação da N atureza - substância única pode ser observado em todas as suas partes, ou modos particulares de existência (incluindo-se aqui o homem), por meio das leis da física, da química e de como estas se organizam nos sistemas biológicos. Dentre estes, a espécie humana, dado o alto grau de complexidade de seu cé rebro, adquiriu a capacidade da razão, à qual são paralelas as capacidades cognitivas de representação, memória, simbolização, intencionalidade etc. (Atlan, 2003a). Tal visão está em clara oposição à representação clássica kantiana da natureza da razão.

Filiando-se a uma releitura espinosista que possa dar sustentação filosófica à nova biologia, Atlan vincula-se à linhagem dos filósofos naturalistas, valorizando, entretanto, a atitude crítica pós-kantiana (1991a,1999a). Por um lado, ele procurará adaptar às descobertas científicas atuais, que parecem comprovar os determinismos que regem o funcionamento dos sistemas vivos, a intuição de um mundo de liberdade e felicidade que nos faria conceber o conhecimento racional do verdadeiro (...) que seria verdadeiro porque decorrente da "verdadeira" natureza do homem. Por outro, alerta-nos de que isto só seria possível quando e se tivermos um conhecimento adequado, isto é, perfeito e completo da natureza do homem, incluindo o da natureza do corpo (Spinoza, Ética II; prop. XIII, esc.), 0 que constitui um particular desafio para a Biologia. Sem o conhecimento adequado, ter-seiam os equívocos das ideologias religiosas ou laicas que se arrogam o conhecimento verdadeiro do que éa natureza em geral ea natureza humana em particular (Atlan, 1999c).

Em seu ensaio de 2002, Atlan sumariza um originalíssimo "experimento do pensamento" (gedankenexperiment), conciliando as conquistas teóricas da ciência com uma reflexão ética informada por sua releitura espinosista, produzindo uma recriação conceitual conjunta. Assim, ele atesta sua participação no consistente movimento contemporâneo que reconhece em Spinoza uma matriz de pensamento não-dicotômico de grande rigor lógico, capaz de alicerçar reconceituações imprescindíveis, nas frontei ras da epistemologia e da ontologia (Chauí, 
1999; N egri, 1993; M acherey, 1992). M ais do que isto, no rastro da intuição discreta de Delbos (2002), investiga a relação possível entre a filosofia espinosista e a ciência natural, indo ao encontro de uma tendência que também aflora nas N eurociências (Damásio, 2003).

0 título do livro A ciência éinumana? Ensaio sobre a livre necessidade condensa, por um lado, o mal-entendido entre a ciência do século 21 e uma Ética e uma Filosofia da Biologia presas ainda a resquícios vitalistas de origem kantiana. Por outro lado, propõe um novo substrato filosófico, o espinosista, para dirimi-lo, adequando uma nova concepção de liberdade à maneira de pensar a nova Biologia. Com efeito, a própria dúvida sobre se um produto privilegiado da condição humana, como a ciência, podeser inumano (ou até "desumano") enraiza-se numa certa tradição humanista kantiana, onde a característica específica do homem, dissociada do determinismo que rege o resto da $\mathrm{Natu-}$ reza, seria o seu livre-arbítrio. Donde, é a questão do livre-arbítrio, reputado como imprescindível ao senso de liberdade e de responsabilidade humanas, que está em foco.

A assertiva kantiana acerca de ser o homem um agente livre estribava-se na teoria biológica, informada pela enteléquia aristotélica, então (e até $o$ início de século 20) vigente, segundo a qual os organismos vivos - com o homem em lugar de destaque - desenvolviam-se de acordo com uma finalidade interna, ao contrário dos seres não-vivos, determinados somente por mecanismos causais. 0 fenômeno da vida, caracterizando-se pela capacidade de reprodução e de adaptação do organismo a mudanças externas, comprovaria a existência de forças vitais irredutíveis às leis físico-químicas. Seria esta capacidade dos homens de se darem os seus próprios fins que fundava a sua possibilidade de liberdade, na concepção da filosofia kantiana.

A revolução biológica do século 20 consistiu exatamente em explicar estes comportamentos pretensamente exclusivos da vida a partir de propriedades físico-químicas das moléculas. Atualmente, a única especificidade do ser vi vo refere-se à complexidade de sua organização e à das funções que a acompanham. Existe, portanto, no plano biológico, um continuum entre o não-vivo e o vivo, entre um mundo sem consciência e a consciência humana, de modo que a própria questão do que seja vida não mais pertença a seus domínios, mas sim àqueles que lidam com as experiências de significação para o homem. Assim, há um hiato cognitivo irredu- tível entre o conhecimento objetivo dos determinismos que nos constituem e nossa experiência de agente eficaz, de escolhas e de responsabilidade.

Este hiato é irresolúvel à luz das filosofias de inspiração kantiana. Atlan propõe, ao invés, um "experimento mental" radical, segundo o qual se prolongariam ficticiamente as descobertas atuais, até o dia em que se explicaria o conjunto dos comportamentos e das escolhas em relação às quais nos sentimos livres. Então, a moral e 0 sentimento de felicidade adequar-se-iam a uma existência e a uma filosofia em que nós nos perceberíamos responsáveis pelo que somos e fazemos, independentemente de uma crença metafísica no livre-arbítrio, admitindo que somos determinados a fazer o que fazemos, mesmo se não o reconhecemos desta forma na experiência cotidiana. Para bem compreendê-lo é imprescindível um esforço intelectual inusual, que ele passa a nos apresentar.

Atlan remete aos "filósofos do determinismo", dentre os quais cita os estóicos, os epicuristas e os autores das tradições filosóficas hebraica, budista e islâmica, com ênfase a Spinoza, pela sua sensibilidade moderna ao tema. A partir daí, Atlan transcreve, nos termos contemporâneos, como se deve dar o fino movimento cognitivo capaz de realizar este movimento inusual. Sugere, então, que aprendamos com os ensinamentos da nova física que, embora algumas de nossas experiências da realidade sejam ilusórias (como as de tempo e de espaço), elas são também reais, no sentido de serem indispensáveis à nossa vida cotidiana. E assim consagra sua cooperação intelectual: Spinoza não dizia outra coisa em seu tempo: o livre arbítrio é uma ilusão ligada à nossa ignorância das verdadei ras causas. Longe de pensar que isto assinalaria a morte de toda a moral, ele intitula, ao contrário, sua maior obra deÉtica. Através dele, nós podemos reencontrar uma outra maneira de pensar a liberdade, que esteja mais de acordo com os avanços atuais da biologia e das ciências humanas.

Para a adequada compreensão do hiato cognitivo exposto por Atlan, o primeiro passo, pois, éir além de nossa forma usual de pensar liberdade e responsabilidade: em um mundo inteiramente determinado pode existir ainda uma liberdade, uma vida em sociedade e uma moral? A contestação de Atlan ao paradigma kantiano é a de que a "livre escolha", escoimada da força das pulsões e dos interesses (os quais contaminariam o julgamento, impelindo a um "livre-arbítrio" ingênuo), elaborada pela razão e obede- 
cendo ao imperativo moral simplesmente não existe. Como as ciências cognitivas, neurológicas e psicológicas demonstram, a distinção kantiana entre escolhas racionais eimpulsivas éilusória do ponto de vista de suas determinações causais, uma vez que o exercício da razão não é desencarnado e a escolha dos fins obedece às leis do desejo e suas determinações psicossociais. 0 sujeito livre kantiano, transitando no domínio supra-sensível da liberdade, fora dos determinismos físicos da $\mathrm{N}$ atureza, seria uma origem absoluta, agente capaz de criar as causas primeiras, iniciando a partir do nada cadeias causais independentes do resto do mundo, qual um "império dentro de um império", como já assinalava Spinoza.

Portanto, segundo Atlan, urge reformular a questão, considerando a liberdade uma experiência radicalmente diferente daquela do livrearbítrio. Como assevera o autor, o "humanismo" decorrente da moral kantiana é, na verdade, anti-humanismo, tendo nutrido horrores morais (como o colonialismo), ao glorificar um $\mathrm{H}$ omem com $\mathrm{H}$ maiúsculo que não existe.

A revolução que devemos empreender é muito mais profunda. Tendo aceitado a hipótese de um mundo totalmente determinado, procedamos ao inverso na nossa maneira usual de lidar com o nosso hiato cognitivo. Para isto, é preciso "esquecer" provisoriamente nossa experiência cotidiana e afetiva do livre-arbítrio e tentar nos acomodar internamente à nossa experiência cognitiva do determinismo.

Para fazêlo, servimo-nos de Spinoza como guia em novas conceituações dos termos em debate. Para este filósofo, a própria Natureza - ou Deus - tem, como corolário de sua existência infinita, uma liberdade que coincide com seu conhecimento infinito das causas necessárias para que se autoproduzam todas as coisas que existem. Esta verdadeira liberdade - livre necessidade - corresponde, pois, à realidade de uma $\mathrm{N}$ atureza autoprodutiva. Ao invés de ser uma capacidade de escolha arbitrária, a liberdade se refere ao fato de não se deixar determinar senão por sua própria lei. Em nosso entendimento de como se dá a transposição destes princípios para o homem, reverbera uma estreita ligação entre ontologia e epistemologia, uma vez que, para nós, a N atureza infinita de Deus se exprime sob dois aspectos, extensão e pensamento.

Assim, a experiência de liberdade humana seria fruto de um processo de aprendizagem, a partir do qual o homem se desembaraça da servidão passiva aos afetos que Ihe diminuem a potência à medida que acede ao conhecimento adequado das coisas e de si mesmo. Agirá, então, determinado apenas pela necessidade de sua própria natureza sem se deixar constranger por cadeias causais a ela al heias.

Observe-se que, segundo a teoria espinosista das paixões, os afetos não se opõem ao conhecimento se são capazes de aumentar a potência humana. Paralelamente, a potência de ordenar os afetos segundo a ordem das razões ou seja, a potência de agir - varia conforme aumente ou diminua o conhecimento adequado da causa dos afetos. Assim, o conhecimento racional espinosista permite englobar, ao compreendêlas, as diversas causas dos fenômenos. Em outro texto (1999c), Atlan cita as similitudes da teoria espinosista com sua própria teoria da auto-organização. Aventa que o aumento e a diminuição da potência de agir correlacionamse com um número maior ou menor de integração de estímulos em diferentes níveis de organização e enfatiza que o conhecimento verdadeiro só é possível se incorporado até ao ponto de adquirir a força de uma paixão.

Atlan reafirma a importância essencial de um postulado inicial de determinismo absoluto. A hipótese do determinismo absoluto é assim ao mesmo tempo um postulado metodológico que precede toda experiência de conhecimento e um postulado ontológico que funda a possibilidade de nossa liberdade. Ou seja, embora jamais possamos atingir ou possuir o conhecimento infinito, aceitar sua existência vira ao avesso a relação entre liberdade e conhecimento. N ossas escoIhas serão entendidas e vividas como inscritas na livre necessidade de uma potência infinita, causa de si em cada um de nós.

Atlan identifica a experiência desta livre necessidade com as ocasiões em que reconhecemos uma intensa atividade do nosso espírito e corpo, exemplificando-o com os momentos privilegiados em que compreendemos al guma coisa. Seria este tipo de atividade que nos instaura como sujeitos. Enquanto estamos, assim, ativos, temos, ao mesmo tempo, a experiência de ser o sujeito do que nós somos e do que fazemos, conciliados com os determinismos da $\mathrm{Na}$ tureza que agem em nós e nos fazem agir.

Continuando a pedagogia sugerida, Atlan nos orienta a retomarmos agora o outro lado do hiato cognitivo que nos constitui, a nossa experiência cotidiana e afetiva de escol has e decisões. Aqui, a novidade existe sempre, pois não podemos sair do tempo, nem o deveríamos, pois Toda a riqueza da existência humana tem a ver com 
o infinito quenós concebemos e com a finitude em que vivemos, embora o inesperado ganhe para nós agora outra dimensão, pois o sabemos relativo à nossa ignorância das causas. N este retorno a nosso modo corriqueiro de pensar, clarificado, entretanto, pela experiência anterior, progressivamente nel e experimentaríamos um sentimento de ser livre característico do adulto e não mais da criança. A criança não escolhe realmente, deixando-se influenciar por desejo, sugestão ou hábito e sente-se livre quando tem a impressão de fazer o que quer; já o adulto, pelo conhecimento de seus próprios determinismos e daqueles do mundo circundante, experimenta, ao agir, o sentimento de exercer sua liberdade com conhecimento de causa.

N um terceiro momento de seu "experimento mental", Atlan delineia duas maneiras de tratarmos nosso hiato cognitivo, que chama de mínima e de máxima. Na modalidade mínima, separamos o esforço intelectual inusual inerente à experiência da "livre necessidade" de nossa experiência usual de "livre-arbítrio". O u seja, por um lado, admitimos intelectualmente a "livre necessidade" que nos rege, dado o conhecimento objetivo dos determinismos. Por outro lado, constatando que vivemos num mundo feito de conhecimentos parciais, experimentamos "escolhas livres". Só temos acesso à "livre necessidade" quando, refletindo sobre as causas que nos fazem agir, reconhecemos que não somos agentes livres. M as em termos pessoais e sociais, mantemo-nos "como se" nossas decisões dependessem de nosso "livre-arbítrio".

Contrariamente, na modalidade máxima procuramos entender as nossas próprias experiências de escolhas livres como signos ou símbolos da verdadeira liberdade. Seriam imagens empobrecidas, mas sempre imagens, da livre necessidade, equivalentes a uma etapa necessária, como a da criança que é ainda "sujeita a" sua história e ao que lhe acontece. Entretanto, podemos adquirir, por um gradual desenvolvimento intelectual, as experiências de liberdade relativas a um conhecimento objetivo. As vivências de escolha livre serão, então, mais do que apenas imagens. Permitirão passar da situação corrente, na qual pensamos escolher de forma indeterminada, a outras em que escolhemos conscientes das causas que nos levam a escoIher. À aproximação da experiência de verdadeira liberdade corresponderia um sentimento crescente de alegria e de aquiescência para com aquilo que em nós é vivido como um processo ativo de conhecimento. Assim, (o) hiato entreli- berdade vivida e liberdade teórica se preenche pouco a pouco, graças à progressão do conhecimento das causas.

Abordando o tema da responsabilidade dentro da mesma hipótese determinista, Atlan ressalta o equívoco, também oriundo da tradição moral kantiana, de que se não há livre-arbítrio, não há liberdade, portanto nem responsabilidade, nem moral. Ao invés, podemos pensar a responsabilidade no seio do determinismo edistinguir responsabilidade de culpabilidade. Atlan se detém nos domínios jurídicos, onde, quanto mais se descobrem as múltiplas causas (neurobiológicas e psicológicas) que impelem ao comportamento criminoso, tanto mais difícil se torna separar a pena do tratamento necessário.

Atlan postulará duas formas de responsabilidade: a priori ou ontológica eaprès coup ou relativa a um estado de fato. A responsabilidade a priori, absoluta e incondicional, é inerente à natureza humana e às suas capacidades de representação, pois devemos responder pelo que somos, em qualquer circunstância. Repercute também num imperativo da dignidade humana, que estabelece que se permanece um ser humano, logo responsável, sejam quaisquer os atos cometidos. Já a responsabilidade après coup enraíza-se em nossa existência cotidiana e surge quando alguém é implicado como uma causa, entre outras, num acontecimento. É aqui que se coloca a questão da culpabilidade, pois mesmo que se tenha sido determinado a agir de uma certa forma, esta experiência foi acompanhada por um estado de consciência, a partir do qual se podem traçar algumas diretrizes em relação aos delitos.

Ainda que o livre-arbítrio seja uma ilusão, o consentimento dos sujeitos em relação a sua vontade - determinada por causas internas e externas - é bem real, afirmando-se como um dado irredutível da natureza humana em sua finitude. Por isso, deve ser levado em conta, mesmo num mundo totalmente determinado. A noção de pessoa, no sentido jurídico, moral e gramatical vincula-se a este estado de consciência. No mundo das experiências afetivas cotidianas é indispensável, para a constituição de sociedades de sujeitos morais responsáveis, que se proceda, até certo ponto, "como se" um livrearbítrio definisse as ações individuais.

A centue-se que tal critério não é uma versão retocada das concepções tradicionais, em que uma maior ou menor capacidade de discernimento separaria culpados de inocentes, dada a assertiva substantiva de que ambos são igual- 
mente responsáveis - em termos ontológicos pelos seus atos. Em conseqüência, a escolha quanto à pena ou tratamento deve avaliar diversos fatores: o peso das duas formas de responsabilidade, o estado de consciência da pessoa na ocasião do delito e sua acessibilidade à sanção ou à terapia. Também a atribuição de responsabilidade al arga-se, englobando todos os envolvidos, de al guma forma, no acontecimento: sempre que tenha havido uma decisão compartilhada, esta implicará uma responsabilidade compartilhada.

Observe-se que a filosofia de Spinoza norteia-se por uma confiança absoluta na capacidade de o homem atingir, por via do Conhecimento, a Felicidade, onde o Bem não se caracteriza, entretanto, por uma oposição absoluta entre o bem e o mal. Esta oposição tenderá a se dissolver pela desaparição de nossa concepção do mal como tal - que não suprime, bem entendido, nossa percepção da dor - e sua substituição por um conhecimento, de certa forma, amoral, dos caminhos pelos quais as coisas se fazem (Atlan, 1999a). Em termos políticos, Spinoza (TTP) não tem dúvidas de que os regimes tirânicos acabarão por sucumbir às suas próprias inadequações, levando Russel $(1967$, v. 3) a atribuir à sua crença "na bondade última do universo" a fleugma com que o filósofo encararia a injustiça e a cruel dade, por estarem circunscritas a dado momento, diante de um determinismo final de perfeição da humanidade. Por outro lado, a noção espinosista de potência - central à sua sutil apreensão da dinâmica intrínseca ao ser, que lhe desvenda os vários determinismos constituintes continuamente - , que apenas assinalamos, faculta extrapolações significativas, de cunho prático, atendendo às urgentes necessidades de reestruturação humana, quer no nível fiIosófico ou psicológico (Deleuze, 2002; M ishari, 2001, 1998; Bove, 1996) quer no político, onde a potência da multitudine coexiste com aquela do indivíduo (Chauí, 2003; N egri, 2002; M atheron, 1988).

Isto posto, voltemos ao texto atlaniano. Dentro da tônica a que acabamos de nos referir, Atlan enfatiza a importância de renovar e aprofundar a reflexão filosófica, à la Spinoza, como prática de pensamento e de vida, lembrando que não podemos continuar a repetir o que se diz há séculos sem levar em conta a formidável mudança operada recentemente. Atlan compara a nossa época aos grandes períodos de transição da humanidade - como o fim do mundo antigo e a revolução científica do século 17 - e insiste num apuro nas redefinições conceituais, como as concernentes ao determinismo, para responder afirmativamente às inéditas exigências do nosso tempo, em prol da liberdade e da felicidade humanas.

\section{Considerações finais}

A ressignificação do termo "humanismo" de acordo com os enquadres conceituais do século 21 , nas fronteiras entre as conquistas científicas ea reflexão filosófica sobre a liberdade e a necessidade, constitui um formidável e estimulante desafio. As autoras deste artigo alinham-se às diversas vertentes da elaboração intelectual que valorizam a atual retomada da confiança na capacidade de transformação do ser humano. Com efeito, temas como o do "progresso" e da "perfectibilidade" do homem são revitalizados (Taguieff, 2004; Passmore, 2004) e a universalidade da razão e a busca da verdade são "reabilitadas" (Nagel, 2001; Davidson, 2002).

Supera-se, pois, com o inegável auxílio dos avanços científicos na diminuição do sofrimento humano (Gould, 2003), o impacto negativo das múltiplas feridas ao longo do século passado que teriam embaçado nossa percepção quanto à continuação (sempre reformulada!) do projeto iluminista iniciado na modernidade (Guillebaud, 2003). Não obstante as dificuldades a este respeito, o trabalho interdisciplinar firma-se como indispensável na maioria dos campos do conhecimento e cissuras como as que opunham nature/nurture, na investigação antropológica, são revistas, inclusive no que concerne à questão do determinismo tratada neste artigo. Diz Saint-Sernin: Sentimos sem dúvida que a antropologia não pode se abstrair nem do meio exterior, de modo que a tecnologia o remodele em caráter permanente, nem do meio interior, cujos segredos são progressivamente desvendados pela biologia molecular. M as mesmo quando conhecermos os constituintes últimos da nossa individualidade, ea carta de nosso genoma estiver levantada e interpretada, ainda teremos, pelo menos, de conduzir e responder a todos estes bilhões de el ementos e operações que, a cada instante, tecem no nosso corpo um destino que é também o nosso (1998).

Devida e academicamente autorizadas para a audácia de propor o prosseguimento/atualização da "revolução antropológica" implícita no "projeto humanista", retomemos a inspiração de Spinoza no Tratado da Correção do I ntelecto. 
Como bem observa Scala (2003), ali o filósofo deixa claro que não há quem não conceba uma natureza humana mais forte que a sua, não há quem não busque adquirir tal natureza. A busca da perfeição seria justamente a de uma natureza humana mais forte que a presente, sendo relevante entender tal "perfeição" não num sentido essencialista, mas corresponden do à passagem de uma perfeição menor a uma perfeição maior, na direção de um maior conhecimento da relação da mente com a $N$ atureza. Seria este conhecimento, 0 da real necessidade de nossa natureza, levando-nos adiante dos equívocos da imaginação, que nos conduziria à ação correta $e$ à Felicidade, ou seja, ao "bem supremo".

Ao explicar em que consiste o "bem supremo" Spinoza revela um "humanismo" sob ótica imprevista - habilmente surpreendida por Atlan, inclusive na segunda epígrafe deste trabaIho. Diz Spinoza: nada obsta (ao homem) a que adquira tal natureza (...): e tudo o que pode ser meio para chegar a isto chama-se verdadeiro bem. 0 sumo bem, contudo, é chegar a gozar com outros indivíduos, se possível, dessa natureza (1973).
Portanto, o que está em questão, nesta exigentíssima concepção de "humanismo", é como pesquisar e proceder para permitir a todos os seres humanos o acesso ao melhor de nossa he rança desde Sócrates: aquela que a partir de nossa condição de autoconhecimento contempla a capacidade de autodeterminação e autogestão de indivíduos e grupos sociais, de acordo com os ditames de sua verdadeira natureza. A grande aposta da Democracia contemporânea é numa Educação em larga e profunda escala, aproveitando todas as descobertas e invenções da Ciência e da Ética como al iadas neste processo. Assim, para que este "humanismo" possa ser implantado, em vez da repetição bem-intencionada de fórmulas desgastadas, faz-se premente um extraordinário esforço, envolvendo amplo concurso de competências interdisciplinares e investindo, em projetos nas fronteiras do $\mathrm{Co}$ nhecimento, o melhor de nossos recursos de dedicação e entusiasmo, de críticas consistentes e de imaginação criadora.

\section{Colaboradores}




\section{Referências bibliográficas}

Abrantes P 1993. N aturalizando a epistemologia, pp. 171218. In F Abrantes (org.). Epistemologia e cognição. Editora da UnB, Brasília.

Aleksandrowicz AM C 2002. Complexidade e metodologia: um refinado retorno às fronteiras do conhecimento, pp. 49-79. In M CS M inayo M CS eSF Deslandes (orgs). Caminhos do pensamento: epistemologia e método. Fiocruz, Rio de Janeiro.

Aristóteles 1985. Política. Tradução, notas e apresentação de Mário da Gama Cury. Editora da UnB, Brasília.

Atlan H 1972. L'organisation biologique et la théorie de I'information. Éditions H erman, Paris.

Atlan H 1979. Entre le cristal et la fumée. Essai sur l'organisation du vivant. Éditions Seuil, Paris.

Atlan $\mathrm{H}$ 1989. Automata network theories in immunology: their utility and their underdetermination. Bulletin of M athematical Biology 51(2):247-253.

Atlan H 1991a. Tout, non, peut-être. Éducation et vérité. Éditions Seuil, Paris.

Atlan H 1991b. Intentional self-organization in nature and the origin of meaning. The role of interpretation, pp. 311-331. In C Rossi \& E Tiezzi (org.). Ecological physical chemistry. Elsevier Editions, Amsterdam.

Atlan H 1991c. L'intuition du complexe et ses théorisations, pp. 9-39. In FF Soulié (org.). Les théories de la complexité autour de l'oeuvre d' Henri Atlan. Éditions Seuil, Paris.

Atlan H 1993. Projet et signification dans des réseaux d'automates. Philosophiques. Revue de la Sociedad de Philolophie du Q uébec XX (2):443-472.

Atlan $\mathrm{H}$ 1995. Le plaisir, la douleur et les niveaux de l'éthique. International Journal of Bioethics 6 (numé ro hors série):53-64.

Atlan H 1998a. Intentional self-organization. Emergence and reduction: towards a physical theory of intentionality. Thesis Eleven 52:5-34.

Atlan H 1998b. Immanent Causality. A spinozist viewpoint on evolution and theory of action. Evolutionary systems. Biological and epistemological perspectives on selection and self-organization. Kluwer Academic Publications, Dordrecht.

Atlan H 1999a. Les étincelles de H asard. Tome: connaissance spermatique. Éditions Seuil, Paris.

Atlan H 1999b. Genealogia e livelli della riflessione etica. Frontiere della Biologia, Encyclopedia Italiana vol. IV: 707-727.

Atlan $\mathrm{H}$ 1999c. Du principe de plaisir à la morale de I'indignation, pp. 289-320. In F Héritier (org.) Dela violence II. Éditions O dile Jacob, Paris.

Atlan H 1999d. Possibilités biologiques, impossibilités socials, pp. 17-41. In H Atlan (org.). Le clonage humain. Éditions Seuil, Paris.

Atlan $\mathrm{H}$ 1999e. La fin de tout génétique? Vers les nouveaux paradigmes en biologie. Éditions INRA, Paris.

Atlan H 1999f. Os níveis de ética, pp. 69-80. In JP Changeux (org). Edusc, Bauru.

Atlan H 2002. La science est-elle inhumaine? Essai sur la libre nécessité. Éditions Bayard, Paris.

Atlan H 2003a. Ruído e determinismo: diálogos espinosistas entre antropologia e biologia. M ana 9(1):123137.

Atlan H 2003b. Les étincelles de H asard. Tomell. Athéisme del'écriture. Éditions Seuil, Paris.
Aubenque P 1978. As filosofias helenísticas: estoicismo, epicurismo, ceticismo, pp. 167-198. In F Châtelet (org.). A filosofia pagã. Editora Zahar, Rio de Janeiro.

Blackburn S 1997. Dicionário Oxford de Filosofia. Editora Zahar, Rio de Janeiro.

Bloom A 1987. 0 declínio da cultura ocidental: da crise da universidade à crise da sociedade. Editora Best Seller, São Paulo.

Bornheim G 1997. Introdução: N otas para o estudo da ética enquanto problema, pp. 7-23. In LM Hühne LM (org.). Ética. Editora U apê-Seaf, Rio de Janeiro.

Bove L 1996. La stratégie du Conatus. Affirmation et résistance chez Spinoza. Éditions Vrin, Paris.

Brun J 1958. Le stoïcisme. Presses Universitaires de France, Paris.

Bunge M 2002. Dicionário de Filosofia. Editora Perspectiva, São Paulo.

Chauí M 1999. A nervura do real: imanência eliberdade em Espinoza. Editora Companhia das Letras, São Paulo.

Chauí M 2003. Política em Espinosa. Editora Companhia das Letras, São Paulo.

Damásio A 2003. Looking for Spinoza: joy, sorrow and the feeling brain. Harcourt Editions, Orlando.

Davidson D 2002. Verdade reabilitada, pp. 129-144. In JRP Ghirardelli, WJ Bendasssolli \& Silva Filho (orgs.). Ensaios sobre a verdade. Editora Unimarco, São Paulo.

Delbos V 2002. 0 espinosismo. Discurso Editorial, São Paulo.

Deleuze G 2002. Espinosa. Filosofia prática. Editora Escuta, São Paulo.

Dennett D 1991. Consciousness explained. Little, Brown and Company, Boston.

Dennett D 1997. Tipos de mentes: rumo a uma compreensão da consciência. Editora Rocco, Rio de Janeiro.

Dennett D 1998. A perigosa idéia de Darwin. A evolução e os significados da vida. Editora Rocco, Rio de Janeiro.

Dilthey G 1944. La esencia de la filosofia. Editorial Losada, Buenos Aires.

Edelman G 1992. Biologia da consciência: as raízes do pensamento. Editora Piaget, Lisboa.

Edelman G 2000. A universe of consciousness: how matter become imagination. Basic Books, N ova York.

Elias N 1985. A condição humana. Editora Difel, Lisboa.

Fukuyama F 2003. N osso futuro pós-humano: conseqüências da revolução da biotecnologia. Editora Rocco, Rio de Janeiro.

Gould SJ 2003. A montanha de moluscos de Leonardo da Vinci. Ensaios sobre história natural. Editora Companhia das Letras, São Paulo.

Guillebaud JC 2003. A reinvenção do mundo. Um adeus ao século XX. Editora Bertrand, Rio de Janeiro.

Habermas 2004.0 futuro da natureza humana. Edições $M$ artins Fontes, São Paulo.

H ottois G 2003. Bioética, riscos tecnológicos e responsabilidades: conflitos de interesses entre gerações presente e futura? Proceedings of the 10 Congresso Estadual de Bioética. Fiocruz, Rio de Janeiro (mimeo).

Jaeger W 1989. Paidéia: a formação do homem grego. Edições M artins Fontes-UnB, São Paulo-Brasília.

Japiassu H \& M arcondes D 1998. Dicionário Básico de FiIosofia. Editora Zahar, Rio de Janeiro.

Kant E 1971. An answer to the question: What is enlightenment? pp. 54-60. In H Resiss (editor). Kant's politi- 
cal writings. Cambridge U niversity Press, Cambridge.

KoyréA 1991. Estudos de história do pensamento científico. Editora Forense Universitária, Rio de Janeiro.

Kurtweil R 2003. Ser humano. Versão 2.0. Caderno M ais. Folha deS. Paulo, 23-03: 4-9.

Lalande A 1988. Vocabulaire Technique et Critique de la Philosophie. Éditions PUF, Paris.

Lessa R 2003. Agonia, aposta e ceticismo: ensaios de filosofia política. UFM G, Belo Horizonte (mimeo).

Long AA \& Sedley DN 2001. Les philosophes hellénistiques. Tome II. Les Stoïciens. Éditions Flammarion, Paris.

Losano M G 1990. H istórias de autômatos. Da Grécia Antiga à Belle Époque. Editora Companhia das Letras, São Paulo.

M acherey P 1992. A vec Spinoza: Études sur la doctrine et I'histoire du spinozisme. Éditions PUF, Paris.

M anifesto de Stanford 2002. Caderno M ais. Folha de S. Paulo, 24-11:5-8.

Matheron A 1988. Individu et communauté chez Spinoza. Éditions de M inuit, Paris.

M ayr E 2004. Para Ernst M ayr, biologia não se reduz às ciências físicas. Caderno M ais. Folha deS. Paulo, 4-07: 3-7.

M ishari R 2001. A felicidade: ensaio sobre a alegria. Editora Difel, Rio de Janeiro.

M ishari R 1998. Le corps et l'esprit dans la philosophie de Spinoza. Le Olessis-Robinson: Synthélabo.

M uñoz AA 2002. Liberdade e causalidade. A ção, metafísica e responsabilidade em Aristóteles. Discurso Editorial \& Fapesp, São Paulo.

Nagel T 2001. A última palavra. Editora da Unesp, São Paulo.

N egri A 1993. A anomalia selvagem: poder e potência em Spinoza. Editora 34, Rio de Janeiro.

Negri A 2002. 0 poder constituinte. Editora DP\&A, Rio de Janeiro.

Oliva A 1990. A hegemonia da concepção empirista de ciência a partir do N ovum Organon de F. Bacon, pp. 11-33. In Oliva A (org.). Epistemologia: a cientificidade em questão. Editora Papirus, Campinas.

Oliveira BJ 2002. Francis Bacon e a Fundamentação da Ciência como Tecnologia. Editora da UFM G, Belo Horizonte.

Passmore J 2004. A perfectibilidade do homem. Editora Topbooks, Rio de Janeiro.
Pegoraro AO 1997. Ética e seus paradigmas, pp. 25-67. In Hühne LM (org.). Ética. Editora U apê-Seaf, Rio de Janeiro.

Pinker S 2004. Tabula rasa. Editora Companhia das Letras, São Paulo.

Prigogine I \& Stengers I 1994. A nova aliança. Editora da UnB, Brasília.

Renault A 1998. 0 indivíduo: reflexão acerca da filosofia do sujeito. Editora Difel, Rio de Janeiro.

Rouanet SP 1987. As razões do lluminismo. Editora Companhia das Letras, São Paulo.

Russell B 1967. História da filosofia ocidental. 3 vols. Editora Companhia Editora N acional, São Paulo.

Saint-Sernin B 1998. A razão no século XX. Editora J osé Olympio-UnB, Rio de Janeiro-Brasília.

Santaella L 2003. Culturas e artes do pós-humano. Editora Paulus, São Paulo.

Santos LG 2003. Ciborges da resistência. Caderno M ais. Folha deS. Paulo, 9-11:8-9.

Santos LHL 2002. A presentação, pp. 9-13. In AA M uñoz (org.) Liberdade e causalidade. Ação, metafísica e responsabilidade em Aristóteles. Discurso Editorial \& Fapesp, São Paulo.

Scala A 2003. Espinosa. Editora Estação Liberdade, São Paulo.

Searle JR 1995. O mistério da consciência. Editora Paz e Terra, Rio de Janeiro.

Searle JR 1997. A redescoberta da mente. Editora M artins Fontes, São Paulo.

Searle JR 2000. M ente, linguagem e sociedade: filosofia no mundo real. Editora Rocco, Rio de Janeiro.

Sibilia P 2002. 0 homem pós-orgânico. Editora RelumeDumará, Rio de Janeiro.

Spinoza B 1973. Tratado de correção do intelecto. Ética. Tratado Político. Correspondência. (Coleção Os Pensadores vol. XVII). Editora Abril Cultural, São Paulo.

Spinoza B 1965. Traité théologique-politique. Éditions Flammarion, Paris.

Taguieff PA 2004. Le sens du progrès: une approche historique et philosophique. Éditions Flammarion, Paris.

YatesFA 1964. Giordano Bruno ea tradição hermética. Editora Cultrix, São Paulo.

Zizek S 2003. A falha da bioética. Caderno M ais. Folha de S. Paulo, 23-06:4-8. 